\title{
On the Mechanism of Attenuation of Current Waves Propagating Along a Vertical Perfectly Conducting Wire Above Ground: Application to Lightning
}

\author{
Yoshihiro Baba, Member, IEEE, and Vladimir A. Rakov, Fellow, IEEE
}

\begin{abstract}
It is known from both theory and numerical simulations that a current pulse suffers apparent attenuation as it propagates along a vertical perfect conductor of uniform, nonzero thickness (e.g., a cylinder) above perfectly conducting ground, excited at its bottom by a lumped source. The associated electromagnetic field structure is non-transverse electromagnetic (TEM), particularly near the source region. On the other hand, it has been shown analytically by Thottappillil $e$ t al. $(2001,2004)$ that no attenuation occurs and the electromagnetic field structure is pure transverse electromagnetic (TEM) if the conductor thickness and source size are assumed to be infinitesimal. The goal of this paper is to examine the mechanism of current attenuation as it propagates along a nonzero thickness conductor, based on the scattering theory and on a nonuniform transmission line approximation. In applying the scattering theory, we decompose the "total" current in the conductor into two components that we refer to as the "incident" and "scattered" currents. The "incident" current serves as a reference (no attenuation), specified disregarding the interaction of resultant electric and magnetic fields with the conductor, while the "scattered" current, found here using the finite-difference time-domain (FDTD) method, can be viewed as a correction to account for that interaction. The scattered current modifies the incident current so that the resultant total current pulse appears attenuated. Thus, the current attenuation is likely to be due to field scattering that does not occur in the case of zero thickness conductor. The attenuation of the total current pulse is accompanied by the lengthening of its tail, such that the total charge transfer is independent of height. Approximation of the vertical conductor above ground by a nonuniform transmission line whose characteristic impedance increases with increasing height is shown to reasonably reproduce the current pulse attenuation predicted by the scattering theory. In this approximation, the apparent current attenuation with height can be attributed to waves reflected back to the source. The results have important implications for development and interpretation of lightning models.
\end{abstract}

Index Terms-Current attenuation, lightning, TEM, transmission line model, vertical conductor.

\section{INTRODUCTION}

$\mathbf{T}$ HE METHOD of moments (MOM) (Harrington [1]) and the finite-difference time-domain (FDTD) method (Yee [2]) for solving Maxwell's equations have recently been applied to finding the distribution of current along the light-

Manuscript received June 14, 2004; revised December 22, 2004. This work was supported in part by Doshisha University and by the National Science Foundation Grants ATM-0003994 and ATM-0346164.

Y. Baba is with the Department of Electrical Engineering, Doshisha University, Kyoto 610-0321, Japan (e-mail: ybaba@mail.doshisha.ac.jp).

V. A. Rakov is with the Department of Electrical and Computer Engineering, University of Florida, Gainesville, FL 32611 USA (e-mail: rakov@ece.ufl.edu).

Digital Object Identifier 10.1109/TEMC.2005.850690 ning channel. Models based on this approach are referred to as electromagnetic models (e.g., Rakov and Uman [3]). In these models (e.g., Podgorski and Landt [4], Moini et al. [5], Kordi et al. [6], Baba and Rakov [7]), lightning return stroke channel is represented by a vertical conductor of nonzero thickness. It has been shown that a current pulse attenuates as it propagates along such a conductor, even in the absence of ohmic losses, when it is excited at its bottom by a lumped voltage source (Bantin [8]; Kordi et al. [9], [10]; Baba and Ishii [11]) or by a lumped current source (Grcev et al. [12], and Baba and Rakov [7]). For example, the current peak decreases from $11 \mathrm{kA}$ to $10 \mathrm{kA}$ over the bottom $300 \mathrm{~m}$ of a vertical perfectly conducting wire of radius $5 \mathrm{~cm}$ in air above perfectly conducting ground (Kordi et al. [10] and Grcev et al. [12]), when a current expected for lightning subsequent return strokes (Nucci et al. [13]) is injected into the wire. The current attenuation predicted by numerical simulations is consistent with theory (e.g., $\mathrm{Wu}$ [14], Chen [15], Lee and Dudley [16]), as shown in Appendix II.

On the other hand, it has been shown analytically (Thottappillil et al. [17], [18]) that no attenuation occurs and electromagnetic field structure is pure TEM if the conductor thickness and source size are assumed to be infinitesimal. This case corresponds to the so-called transmission line (TL) model (Uman and McLain [19]), not to be confused with distributed-circuit ( $R-L$ $C$ ) models (e.g., Rakov and Uman 1998 [3]). The TL model with return-stroke speed, $v$, equal to the speed of light $c$ can be visualized, based on the transmission line theory, as a zeroradius vertical perfectly conducting wire and its image excited at their junction point by an infinitesimal source, as shown in Fig. 1(a). The image can be viewed as the return path for the vertical wire, and vice versa. An equivalent representation, based on the waveguide theory, is a zero-radius vertical perfectly conducting wire above perfectly conducting ground excited at its bottom by a spherical TEM wave (Kordi et al. [10]), as shown in Fig. 1(b). These two visualizations require a hypothetical zero-radius vertical wire, which cannot be realized in practice or in numerical techniques. The most general and rigorous representation of the TL model, based on the antenna theory, is a vertical phased current source array (Baba and Rakov [7]), shown in Fig. 1(c). Each current source is activated when an upward moving return stroke front reaches its altitude. This latter representation is valid for any return stroke speed $v$ and any channel radius.

There appears to be no consensus regarding the reason (or reasons) for current attenuation predicted by the electromagnetic lightning models. According to Kordi et al. [9], [10], 


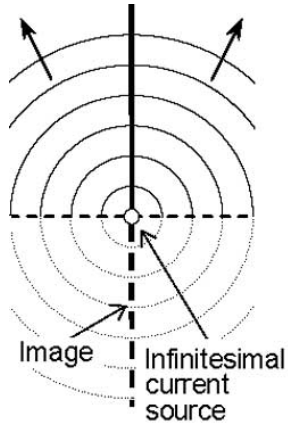

(a)

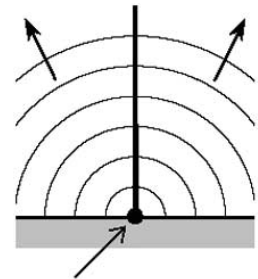

Spherical-TEM-wave source

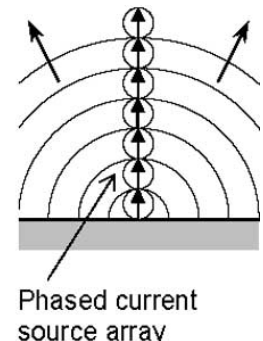

source array
Fig. 1. Visualization of the lightning return stroke TL model, $I\left(z^{\prime}, t\right)=$ $I\left(0, t-z^{\prime} / v\right)$, with $v=c$. Semicircular solid lines and slanted arrows represent an outward propagating spherical TEM wave front. (a) Visualization based on the classical transmission line theory: a vertical wire and its image excited by an infinitesimal source, valid only for $v=c(v<c$ would imply a medium other than air) and a zero radius lightning channel $(L=\infty, C=0$ where $L$ and $C$ are the inductance and capacitance, each per unit length). A spherical TEM field structure is required for the classical transmission line the ory to be applicable. (b) Visualization based on the waveguide theory: a vertical wire above ground excited at its bottom by a spherical TEM wave, valid only for $v=c(v<c$ would imply a medium other than air $)$ and a zero radius lightning channel. (c) Visualization based on the antenna theory: a vertical phased current source array above ground, valid for any lightning return stroke speed, $v$, and any lightning channel radius. This is the most general and rigorous representation of the TL model. Note that for the case of $v<c$, the electromagnetic field structure is not TEM.

the current attenuation and dispersion necessarily occur when a vertical nonzero radius wire is excited by a non-TEMwave source. Baba and Rakov [7] simulated spherical TEM wave excitation using an appropriate phased current source array and observed current attenuation above the excitation region. In view of the absence of ohmic losses, the observed current attenuation was attributed to "radiation losses" (e.g., Kordi et al. [9], [10]; Baba and Ishii [11]). Thottappillil and Uman [20] suggested that a vertical cylinder above ground can support an unattenuated current if this cylinder is excited at its base by a circular ensemble of TEM wave sources. On the other hand, Baba and Rakov [7] have pointed out that the characteristic impedance of a vertical cylinder above ground varies with height, which implies that pulses propagating along such a cylinder in general cannot preserve their amplitude and shape. Bermudez et al. [21] stated that the controversy regarding the validity of uniform transmission line representation for a vertical conductor above ground "is not settled yet." One of the reasons for the contradictory views found in the literature is the lack of understanding of the mechanism of attenuation of current waves propagating along a perfectly conducting wire.

In this paper, we will attempt to explain the mechanism of the current attenuation based on the scattering theory and on a nonuniform transmission line approximation. In applying the scattering theory, we decompose an attenuated "total" current pulse $I_{\text {tot }}$, propagating on a vertical nonzero-thickness perfect conductor into an "incident" unattenuated current pulse, $I_{\mathrm{inc}}$, and an induced or "scattered" current pulse, $I_{\text {scat }}$ (evaluated as $\left.I_{\text {tot }}-I_{\text {inc }}\right)$. This is equivalent to finding a correction to the initially assumed reference (no attenuation) current, $I_{\text {inc }}$, in the conductor, this correction, $I_{\text {scat }}$, accounting for the interaction

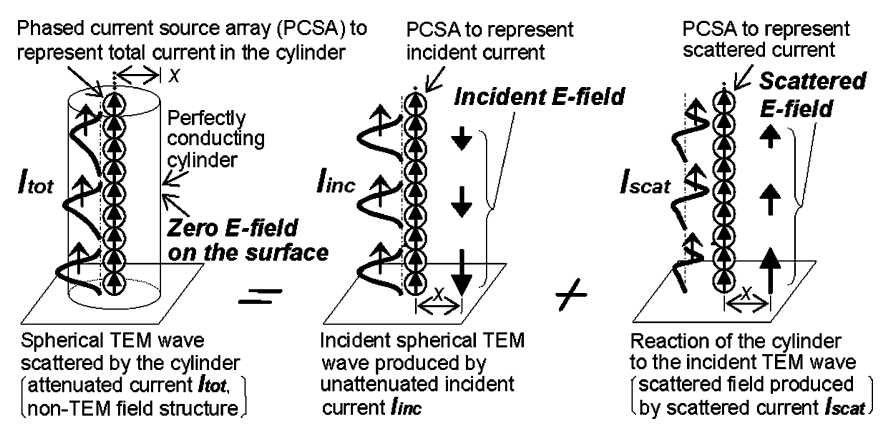

Fig. 2. Conceptual picture to explain the mechanism of current attenuation along a vertical nonzero thickness perfect conductor above perfectly conducting ground. All currents are assumed to flow on the axis. An attenuated "total" current pulse $I_{\text {tot }}$ is separated into an "incident" unattenuated current pulse $I_{\text {inc }}$ and a "scattered" current pulse $I_{\text {scat }}$. $I_{\text {inc }}$ generates an incident downward vertical electric field at a horizontal distance $x$ from the axis (on the lateral surface of the cylinder). $I_{\text {scat }}$ produces a scattered upward vertical electric field that cancels the incident downward vertical electric field on the surface of the cylinder, and modifies the incident current $I_{\text {inc }}$. The resultant current pulse, $I_{\text {tot }}=I_{\text {inc }}+I_{\text {scat }}$, appears attenuated and its tail is lengthened as this pulse propagates along the conductor.

of resultant electric and magnetic fields with the conductor. Each of the three currents is assumed to flow on the axis of the conductor and is represented by an appropriate vertical phased current source array (see Fig. 2). Our goal is to examine the mechanism of current attenuation along a nonzero-thickness vertical perfectly conducting wire; in other words, to show the reason why a nonzero-thickness vertical perfectly conducting wire (as opposed to a zero-thickness wire) cannot support "unattenuated" current propagation. This is why we introduce "unattenuated" incident current $I_{\text {inc }}$ as the reference point. An incident unattenuated current $I_{\text {inc }}$ transporting positive charge upward generates an incident downward vertical electric field. We will show that the corresponding scattered current pulse $I_{\text {scat }}$ produces an upward-directed scattered electric field that, as expected, cancels the incident downward vertical electric field on the surface of the perfect conductor. This result indicates that the current pulse attenuation occurs in order to satisfy the boundary condition on the tangential component of electric field on the surface of a perfect conductor. Fig. 2 shows the conceptual picture of this mechanism. Note that placing the equivalent filamentary current on the axis and matching the field boundary conditions on the surface is equivalent to assuming the equivalent filamentary current on the surface and placing matching points on the axis (e.g., Balanis [22]). In the nonuniform transmission line approximation, the apparent current attenuation with height can be attributed to waves reflected back to the source.

The structure of this paper is as follows. In Section II, using Thottappillil et al.'s [17] analytical equation, we examine the incident vertical electric field, $E_{\text {inc }}$, which can be viewed as generated by an incident unattenuated current pulse $I_{\text {inc }}$. In Section III, using the FDTD method, we find the total current $I_{\text {tot }}$ needed to satisfy the boundary condition on the electric field on the surface of a vertical conductor of nonzero thickness. We show that $I_{\text {tot }}$ is attenuated, and that its shape changes, so that no charge is deposited on the conductor. In Section IV, we find the scattered current $I_{\text {scat }}$ as the difference between the total and incident currents $\left(I_{\text {tot }}-I_{\text {inc }}\right)$. We examine the 
relation of $I_{\text {scat }}$, which can be viewed as a correction to the initially assumed unattenuated current, $I_{\text {inc }}$, to the attenuation of the total current pulse and lengthening of its tail. In Section V, we examine the dependencies of current attenuation on conductor thickness, frequency, and source length. In Section VI, we show that a nonuniform transmission line whose characteristic impedance increases with increasing height can reasonably reproduce the current pulse attenuation observed using the FDTD method in Section III. In Appendix I, we explain the reason for less attenuation in the case of a horizontal conductor. In Appendix II, we compare total current waveforms calculated using the FDTD method with those calculated using an analytical equation derived by Chen [15] for an infinitely long, perfectly conducting cylinder excited by a delta-gap step voltage source. In Appendix III, we examine the electric field structure around a nonzero-thickness perfect conductor. In Appendix IV, we show the dependencies of magnitude of the longitudinal electric field, produced by a short current dipole, on horizontal distance from the current dipole and on pulse width, which are used in Section $\mathrm{V}$ to explain the dependencies of current attenuation on conductor thickness and on frequency.

\section{INCIDENT CURRENT $\left(I_{\mathrm{inc}}\right)$, INCIDENT E-FIELD $\left(E_{\mathrm{inc}}\right)$ : ANALYTICAL SOLUTION}

In the TL model, the longitudinal current $I\left(z^{\prime}, t\right)$ in a straight and vertical lightning channel at an arbitrary height $z^{\prime}$ and time $t$ is expressed as follows:

$$
I\left(z^{\prime}, t\right)=I\left(0, t-z^{\prime} / v\right)
$$

where $v$ is the return-stroke speed and $I(0, t)$ is the channel-base current. Typical values of $v$ are one-third to two-thirds of $c$ (e.g., Rakov [23]). In this paper, we will assume that $v=c$, as done by Thottappillil et al. [17], Kordi et al. [9], [10]; and Baba and Rakov [7], in order to simplify the analysis aimed at identifying the mechanism of current attenuation with height.

Baba and Rakov [7] showed numerically that a vertical phased current source array activated so as to satisfy (1) with $v=c$ produced a spherical TEM wave [see Fig. 1(c)]. The corresponding analytical solution is found by Thottappillil et al. [17], with the electric field equation being given by

$$
E_{\theta}(r, \theta, t)=\frac{1}{2 \pi \varepsilon_{0} c r \sin \theta} I(0, t-r / c), \quad \theta \neq 0
$$

where $r$ is the inclined distance from the channel origin to an observation point, and $\theta$ is the angle between the channel and a straight line passing through both the channel origin and the observation point. Note that (2) accounts for the electrostatic, induction, and radiation field components (Thottappillil et al. [17], Fig. 2). The $r^{-1}$ dependence of the total electric field is due to the assumption $v=c$ (return stroke front moves at the same speed as electromagnetic signal). We will use a vertical, zerothickness phased current source array to generate an incident spherical TEM wave. We will refer to the source current distribution [given by (1)] as the "incident" unattenuated current $I_{\text {inc }}$. This current is shown in Fig. 3. Although other $I_{\text {inc }}$ are possible for the same $I_{\text {tot }}$, our choice is the best for examining the mechanism of current attenuation with height. Then, in Section

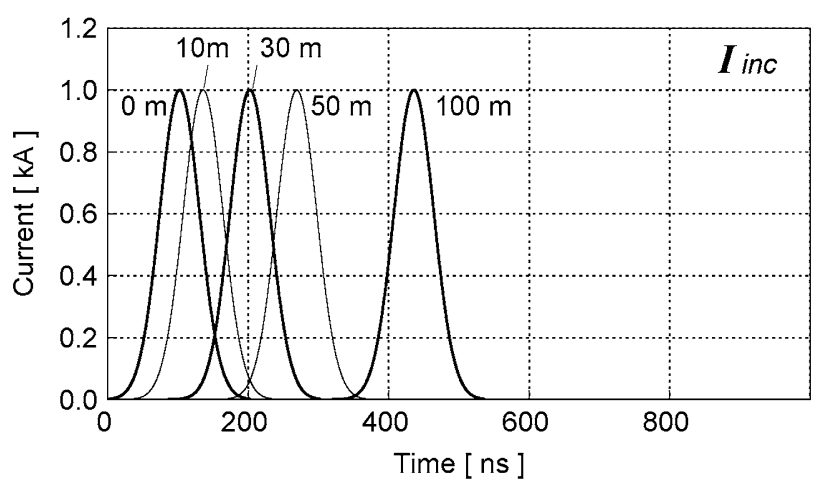

Fig. 3. Incident current, $I_{\text {inc }}$, waveforms at different heights produced by a vertical phased current source array, each source generating a pulse having a magnitude of $1 \mathrm{kA}$ and a half peak width of $67 \mathrm{~ns}$.

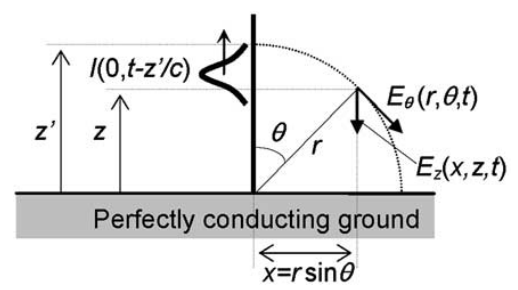

Fig. 4. Phased current source array of zero thickness above perfectly conducting ground, activated as specified by (1) with $v=c . E_{z}(x, z, t)$ represents the incident vertical electric field $E_{\text {inc }}$.

TABLE I

Magnitudes of DownWard Vertical Electric Field, $E_{\text {inc }}$, In kV/m AT A Radial Distance $x(x=0$ MAY BE VIEWED AS $x \rightarrow 0)$ From the AXIS OF A Vertical Phased CurRent Source Array and at a Height $z$ Above the Ground Plane, Calculated Using (3). CurRent Magnitude Is SET AT $1 \mathrm{kA}$. DOWNWARD FIELD Is DEFINED AS Positive

\begin{tabular}{c|rrrrr}
\hline & \multicolumn{5}{|c}{$z, \mathrm{~m}$} \\
\cline { 2 - 6 }$x, \mathrm{~m}$ & 0 & 0.1 & 1 & 10 & 100 \\
\hline 0 & $\infty$ & 600 & 60 & 6.0 & 0.60 \\
0.1 & 600 & 420 & 60 & 6.0 & 0.60 \\
1.0 & 60 & 60 & 42 & 6.0 & 0.60 \\
\hline
\end{tabular}

III, we will consider a vertical nonzero-thickness conductor and find the distribution of current $I_{\text {tot }}$ along this conductor needed to satisfy the boundary condition on the electric field on its surface, using the FDTD method. The difference between $I_{\text {tot }}$ and $I_{\text {inc }}$ can be viewed as the scattered current $I_{\text {scat }}=I_{\text {tot }}-I_{\text {inc }}$.

The vertical electric field component $E_{z}$ at a horizontal distance $x$ from the axis and at a height $z$ above ground plane is given by

$$
\begin{aligned}
E_{z}(x, z, t) & =E_{\theta}(r, \theta, t) \cos \left(\frac{\pi}{2}-\theta\right) \\
& =\frac{1}{2 \pi \varepsilon_{0} c r} I(0, t-r / c) \\
& =\frac{1}{2 \pi \varepsilon_{0} c \sqrt{x^{2}+z^{2}}} I\left(0, t-\sqrt{x^{2}+z^{2}} / c\right)
\end{aligned}
$$

and illustrated in Fig. 4.

Table I shows magnitudes of downward vertical electric field calculated using (3) along and around the vertical zero-thickness phased current source array, which represents an incident 


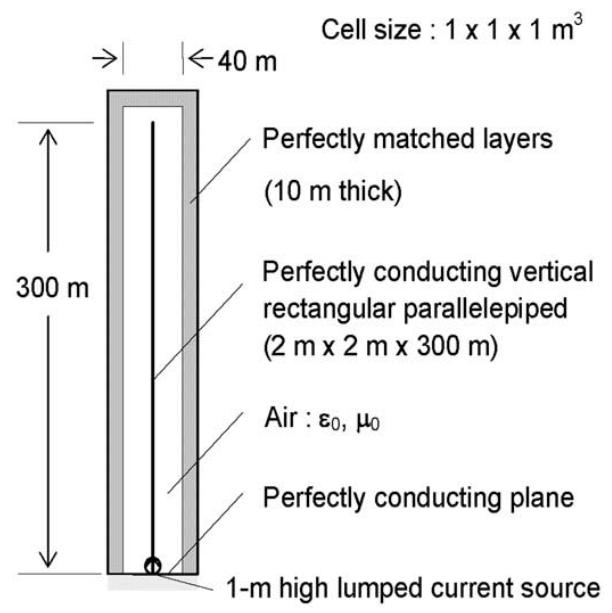

Fig. 5. A vertical perfectly conducting parallelepiped having a cross sectional area of $2 \times 2 \mathrm{~m}^{2}$ in air on a perfectly conducting plane excited at the bottom by a 1 -m high current source. Current, $I_{\text {tot }}$, in this conductor corresponding to zero vertical electric field $\left(E_{\text {tot }}=0\right)$ on the surface of conductor is found using the FDTD method. The working volume of $40 \times 40 \times 310 \mathrm{~m}^{3}$ is surrounded by perfectly matched layers (PML) of thickness $10 \mathrm{~m}$, except for the bottom, where the volume is limited by the perfectly conducting plane.

unattenuated positive current pulse $I_{\text {inc }}$ having a magnitude of $1 \mathrm{kA}$ and propagating upward with $v=c$. Interestingly, the tangential (vertical) component of electric field at $x=0$ is nonzero (approaches a nonzero value as $x$ approaches zero, $x \rightarrow 0$ ), implying that the phased current source array cannot be viewed as a vertical perfectly conducting cylinder of zero radius. In this case, the TEM field structure is maintained due to the fact that, although the vertical component of electric field at $x=0 \mathrm{~m}$ is nonzero, its radial component (the same as the theta component at $x=0 \mathrm{~m}$ ) is infinitely large. The downward vertical electric field along a zero-thickness array $(x=0 \mathrm{~m}, z \neq 0)$ varies as inverse height $(1 / z)$. Away from the array $(x>0 \mathrm{~m})$, the vertical electric field decreases with increasing height more slowly than the inverse proportionality at relatively small heights (near the source region), and decreases approximately as the inverse height beyond that region.

Note that for two parallel vertical phased current source arrays, the vertical electric field decays with height much faster than inverse height in the case of a single vertical phased current source array and vanishes within distances exceeding several times the spacing between the two parallel current source arrays (Appendix I-A). This observation has implications for the case of horizontal wires above ground, considered in Appendix I-B.

\section{Total Current $\left(I_{\text {tot }}\right)$, Total E-Field $\left(E_{\text {tot }}\right)$ : NUMERICAL SOLUTION}

In order to simulate a spherical TEM wave modified by the presence of nonzero-thickness conductor and find associated current, $I_{\text {tot }}$, in the conductor (see Fig. 2), we consider a vertical perfectly conducting parallelepiped having a cross sectional area of $2 \times 2 \mathrm{~m}^{2}$ in air on a perfectly conducting plane, excited at its bottom by a $1 \mathrm{~m}$ high current source (Fig. 5). The solution will be found using the FDTD method designed for rectangular geometry. Conclusions based on this solution are also applicable

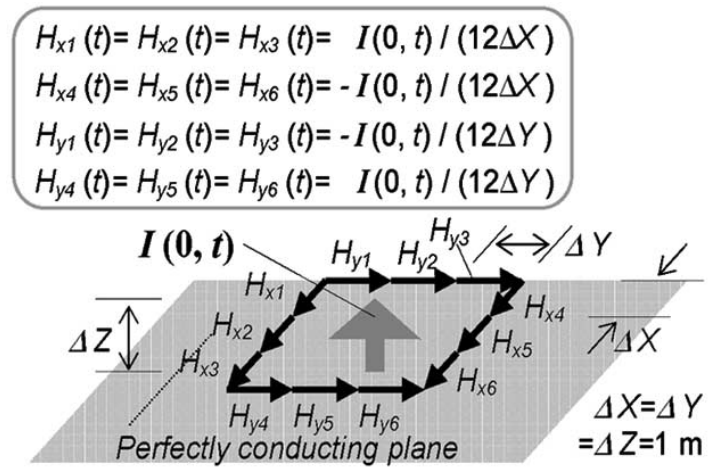

Fig. 6. Specification of $1 \mathrm{~m}$ high current source at the bottom of the $2 \times 2 \times$ $300 \mathrm{~m}^{3}$ vertical parallelepiped shown in Fig. 5 .

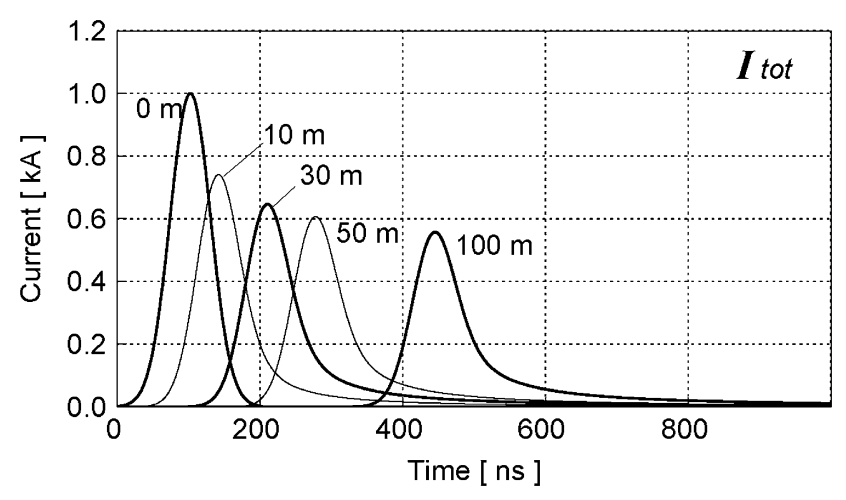

Fig. 7. Total current waveforms, $I_{\text {tot }}$, at different heights calculated using the FDTD method for a vertical perfectly conducting parallelepiped having a cross sectional area of $2 \times 2 \mathrm{~m}^{2}$ in air on a perfectly conducting plane excited at its bottom by a $1 \mathrm{~m}$ high lumped current source. This current source produces a Gaussian pulse having a magnitude of $1 \mathrm{kA}$ and a half peak width of $67 \mathrm{~ns}$.

to the cylindrical geometry discussed above. The total current $I_{\text {tot }}$ minus the incident current $I_{\text {inc }}$ will yield the scattered current $I_{\text {scat }}$. As noted above, this procedure can be viewed as finding a correction, $I_{\text {scat }}$, to the initially assumed unattenuated current, $I_{\text {inc }}$, needed to account for the reaction of the conductor. Alternatively, $I_{\text {scat }}$ could be obtained setting $E_{\text {scat }}=-E_{\text {inc }}$ on the surface of the conductor and solving for $I_{\text {scat }}$ on its axis.

The working volume of $40 \times 40 \times 310 \mathrm{~m}^{3}$, shown in Fig. 5, is divided into $1 \times 1 \times 1 \mathrm{~m}^{3}$ cubic cells. Perfectly matched layers (PML) (Berenger 1994 [24]) (absorbing boundaries) are set at the top and sides of the volume in order to avoid reflections there. At the bottom, the volume is limited by a perfectly conducting plane that is simulated by forcing the tangential components of electric field at the boundary to be zero. This latter method is also used to simulate vertical perfectly conducting parallelepiped.

The current source is represented, as illustrated in Fig. 6 , by specifying 121 -m-long magnetic-field elements, $H_{x 1}(t), H_{y 1}(t)$, and so on (that is, $3 \times 3 \mathrm{~m}^{2}$ magnetic-field loop), surrounding the bottom $2 \times 2 \times 1 \mathrm{~m}^{3}$ section of the vertical parallelepiped.

Fig. 7 shows current waveforms at different heights calculated using the FDTD method with a time increment of 1.25 ns for the vertical perfectly conducting parallelepiped shown in Fig. 5. The current source produces a Gaussian pulse having a 


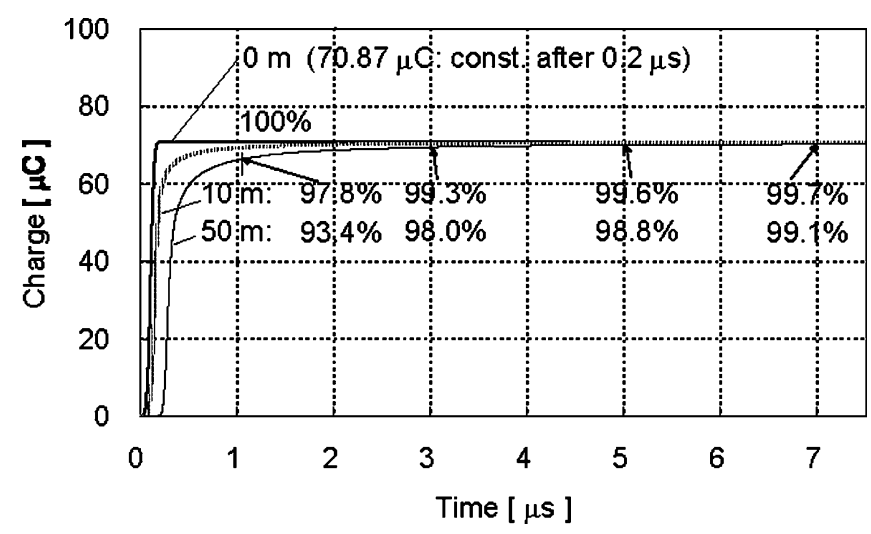

Fig. 8. Time integrals of current at heights 0,10 , and $50 \mathrm{~m}$ calculated using the FDTD method for a $1200 \mathrm{~m}$ long vertical perfectly conducting parallelepiped having a cross sectional area of $2 \times 2 \mathrm{~m}^{2}$ in air on a perfectly conducting plane excited at its bottom by a $1 \mathrm{~m}$ high lumped current source, which produces a Gaussian pulse having a magnitude of $1 \mathrm{kA}$ and a half peak width of $67 \mathrm{~ns}$.

magnitude of $1 \mathrm{kA}$ and a half-peak width of $67 \mathrm{~ns}$. The current pulse propagates upward with attenuation, which is most significant within the bottom $20 \mathrm{~m}$, while the risetime of the current pulse is almost constant. Within the bottom $20 \mathrm{~m}$, the average propagation speed is $0.9 c$, evaluated tracking the pulse peak, or $0.95 c$, evaluated tracking the pulse rising edge that is defined as $1 \%$ level of the corresponding peak on the rising edge, and is essentially equal to $c$ at larger heights.

As seen in Fig. 7, the current pulse attenuation is accompanied by the lengthening of its tail. Fig. 8 shows the time integral of current at heights 0,10 , and $50 \mathrm{~m}$ calculated using the FDTD method for a $1200-\mathrm{m}$ long vertical perfectly conducting parallelepiped having a cross-sectional area of $2 \times 2 \mathrm{~m}^{2}$ excited at its bottom by a 1-m high lumped current source. It is clear from Fig. 8 that, as time approaches infinity, the charge transferred through each section of the conductor tends to be equal to the charge supplied by the source. In other words, as time approaches infinity, charge on the conductor approaches zero. This result possibly suggests that no energy is lost from the system (composed of an infinitely long vertical conductor above an infinitely large ground plane). If so, then, the apparent current attenuation, often viewed as being due to "radiation losses," can be attributed to the redistribution of energy between electric and magnetic fields that is needed to satisfy the boundary conditions on the surface of perfect conductor. An apparently equivalent interpretation in terms of the nonuniform transmission-line theory is presented in Section VI.

\section{Scattered CuRRent $\left(I_{\text {scat }}\right)$, SCATtered E-Field

$$
\left(E_{\text {scat }}\right): I_{\text {scat }}=I_{\text {tot }}-I_{\text {inc }}, E_{\text {scat }}=-E_{\text {inc }}
$$

In this Section, we find the scattered current as $I_{\text {scat }}=$ $I_{\mathrm{tot}}-I_{\mathrm{inc}}$, which is responsible for the apparent attenuation of the total current $I_{\text {tot }}$ with height. The total current waveforms $I_{\text {tot }}$ at different heights, calculated using the FDTD method for a vertical perfectly conducting parallelepiped having a cross sectional area of $2 \times 2 \mathrm{~m}^{2}$ in air, are shown in Fig. 7. The corresponding incident current waveforms $I_{\text {inc }}$, given by (1) for $v=c$, are shown in Fig. 3. Fig. 9 shows wave-

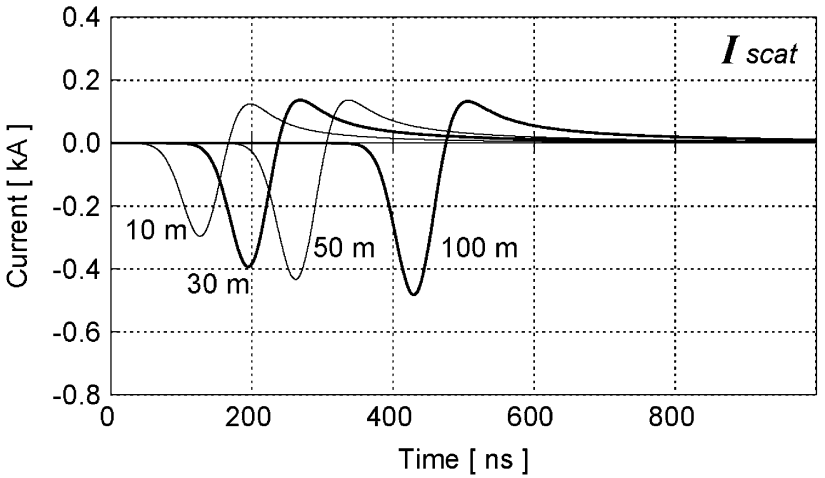

Fig. 9. Scattered current waveforms, $I_{\text {scat }}$, at different heights obtained as the difference between corresponding waveforms shown in Figs. 7 and 3 ( $I_{\text {scat }}=$ $\left.I_{\text {tot }}-I_{\text {inc }}\right)$.

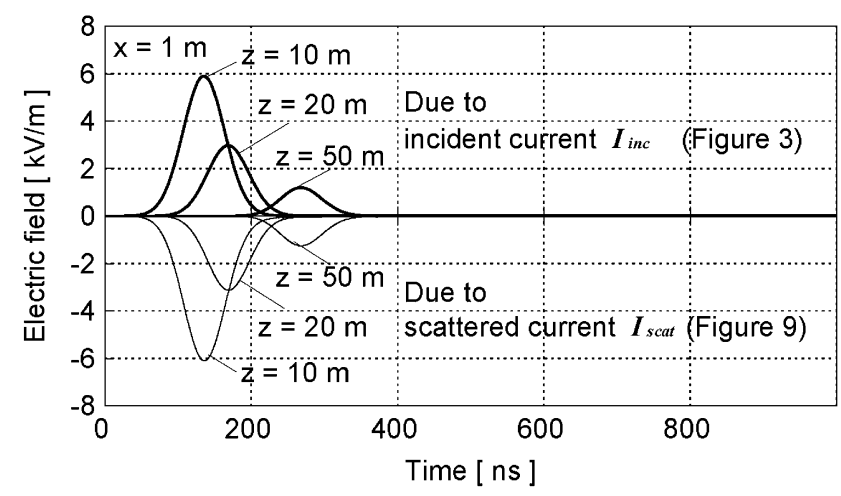

Fig. 10. Waveforms of vertical electric field at a horizontal distance $x=1 \mathrm{~m}$ from the conductor axis and at heights $z=10,20$, and $50 \mathrm{~m}$ calculated using appropriate phased current source arrays. Downward electric field is defined as positive. The positive unipolar waveforms are calculated using $I_{\text {inc }}$ shown in Fig. 3 (these waveforms can also be obtained using (3)), and the negative unipolar waveforms are calculated using $I_{\text {scat }}$ shown in Fig. 9. Each source of the phased current source array is represented by a $1 \times 1 \mathrm{~m}^{2}$ magnetic field loop surrounding the conductor axis.

forms of $I_{\text {scat }}=I_{\text {tot }}-I_{\text {inc }}$ (the difference between the waveforms shown in Figs. 7 and 3). The scattered current $I_{\text {scat }}$ has a bipolar waveshape with the initial half cycle having a polarity that is opposite to that of the incident current $I_{\text {inc }}$. Thus, $I_{\text {scat }}$ is responsible for the apparent attenuation of $I_{\text {tot }}$ with height. The second half cycle of $I_{\text {scat }}$ has the same polarity as $I_{\text {inc }}$ and causes the lengthening of the total current pulse tail. Since $I_{\text {tot }}$ deposits no charge on the vertical perfect conductor (see Fig. 8), the time integral of $I_{\text {scat }}$ is equal to zero (as time approaches infinity).

Fig. 10 shows waveforms of the vertical electric field at a horizontal distance $x=1 \mathrm{~m}$ from the conductor axis and at heights $z=10,20$, and $50 \mathrm{~m}$ in air due to $I_{\text {inc }}$ (Fig. 3) and $I_{\text {scat }}$ (Fig. 9). The scattered electric fields $E_{\text {scat }}$ (negative unipolar waveforms in Fig. 10) were calculated using the scattered current distribution $I_{\text {scat }}$ (Fig. 9) as the outputs of a vertical phased current source arrays (see Fig. 2). The incident electric fields $E_{\text {inc }}$ (positive unipolar waveforms in Fig. 10) were calculated similarly using the incident current distribution $I_{\text {inc }}$ (Fig. 3) as the outputs of a vertical phased current source arrays (or, equivalently, using (3)). Each current source was represented by specifying four 1 -m long magnetic-field elements $\left(1 \times 1 \mathrm{~m}^{2}\right.$ magnetic-field 


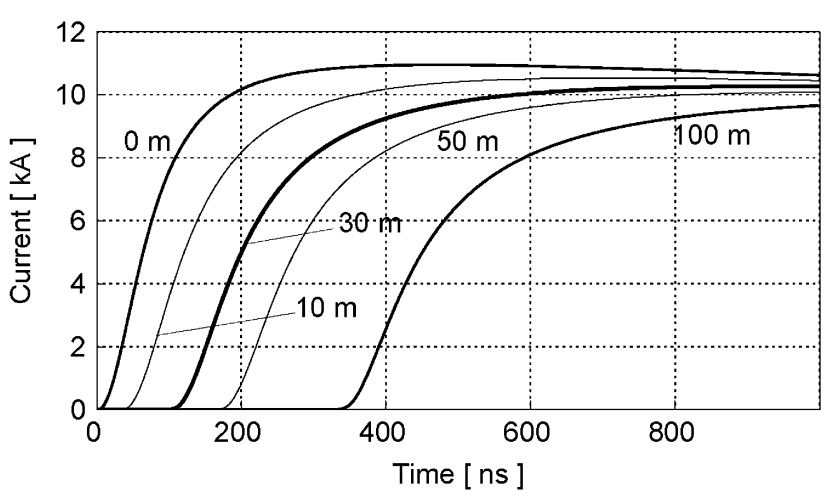

Fig. 11. Current waveforms at different heights calculated using the FDTD method for a vertical perfectly conducting parallelepiped having a cross sectional area of $2 \times 2 \mathrm{~m}^{2}$ in air on a perfectly conducting plane excited at its bottom by a $1 \mathrm{~m}$ high lumped current source. This current source produces a current pulse representative of lightning subsequent return strokes. See Nucci et al. [13].

loop) surrounding the conductor axis, as described above. The scattered current $I_{\text {scat }}$, which is responsible for the reduction of $I_{\text {tot }}$ pulse magnitude, produces a scattered upward vertical electric field that, as expected, cancels the incident downward vertical electric field $1 \mathrm{~m}$ away from the conductor axis. Thus the current attenuation is likely to be due to field scattering that does not occur in the case of zero-thickness conductor. As noted above, $I_{\text {scat }}$ is also responsible for the lengthened wavetail of the total current $I_{\text {tot }}=I_{\text {inc }}+I_{\text {scat }}$. It follows from Table I and (3) that a current pulse attenuates significantly near the source region, and that attenuation reduces with increasing height.

Both incident and scattered fields contribute to the overall electromagnetic field structure. Near the vertical conductor, the vertical electric field due to $I_{\text {scat }}$ decays with increasing horizontal distance $x$ considerably faster than that due to $I_{\text {inc. As }}$ a result, the TEM field structure due to $I_{\text {inc }}$ is disturbed in the vicinity of the conductor. At larger distances, the fields due to $I_{\text {inc }}$ and $I_{\text {scat }}$ decay at about the same rate, so that the overall electromagnetic field structure becomes more or less TEM (see Appendix III).

Note that the same solution for $I_{\text {scat }}$ would be obtained if we placed a large number of phased current source arrays, whose total current equals to $I_{\text {inc }}$, on the lateral surface of the cylinder and required a zero total vertical electric field on the axis of the cylinder. This formulation is apparently equivalent to the vertical cylinder excited at its base by a circular ensemble of TEM wave sources considered by Thottappillil and Uman [20].

\section{Dependences of Current AtTenuation on the Source LENGTH, CONDUCTOR THICKNESS, AND FREQUENCY}

Besides the base case, 1-m high current source, $2 \times 2 \mathrm{~m}^{2}$ cross-sectional area parallelepiped, $67 \mathrm{~ns}$ half-peak width Gaussian pulse, presented in Section III, we performed calculations also for the following conditions: 1) a 2-m high current source; 2) a vertical perfectly conducting parallelepiped having a $1 \times$ $1 \mathrm{~m}^{2}$ cross sectional area; and 3) a $33 \mathrm{~ns}$ half-peak width Gaussian pulse. Table II shows the dependency of current attenuation on the source height, Table III on the thickness of vertical
TABLE II

Magnitudes of Current Pulses, $I_{\text {tot }}$, At DifFerent Heights (IN PERCENT of the Magnitude at $z^{\prime}=0$ ) CALCUlated Using THE FDTD METHOD FOR A Vertical Perfectly Conducting Parallelepiped HaVing a CROSS SECTIONAL AREA OF $2 \times 2 \mathrm{~m}^{2}$. THE VERTICAL CONDUCTOR Is EXCITED AT ITS BOTTOM BY A 1 OR 2 m High LUMPED CURRENT SOURCE, WHICH PRODUCES a Gaussian Pulse Having a Half-PEAK Width of $67 \mathrm{~ns}$

\begin{tabular}{l|rrrrrr}
\hline \multirow{2}{*}{$\begin{array}{l}\text { Source height, } \\
\mathrm{m}\end{array}$} & 0 & 10 & 20 & 50 & 100 \\
\cline { 2 - 6 } 1 & 100 & 74 & 68 & 61 & 56 \\
2 & 100 & 79 & 72 & 64 & 59 \\
\hline
\end{tabular}

TABLE III

Magnitudes of Current Pulses, $I_{\text {tot }}$, At Different Heights (IN PERCENT OF the Magnitude at $z^{\prime}=0$ ) Calculated Using the FDTD Method FoR VERTICAL PERFECTLY CONDUCTING PARALlELEPIPEDS HAVING CROSS SECTIONAL AREAS OF $2 \times 2 \mathrm{~m}^{2}$ AND $1 \times 1 \mathrm{~m}^{2}$ ON A PERFECTLY CONDUCTING Plane. THE VerticAl CONDUCTOR IS EXCITED AT ITS BOTTOM BY A $1 \mathrm{~m}$ High Lumped Current Source, Which Produces a Gaussian Pulse HAVING A HALF-PEAK WIDTH OF 67 ns

\begin{tabular}{l|rrrrr}
\hline \multirow{2}{*}{$\begin{array}{l}\text { Cross-sectional } \\
\text { area }\end{array}$} & 0 & 10 & 20 & 50 & 100 \\
\hline & 100 & 79 & 73 & 66 & 61 \\
$1 \times 1 \mathrm{~m}^{2}$ & 100 & 74 & 68 & 61 & 56 \\
\hline
\end{tabular}

TABLE IV

Magnitudes of Current Pulses, $I_{\text {tot }}$, At Different Heights (IN PERCENT OF the Magnitude at $z^{\prime}=0$ ) Calculated Using The FDTD Method FoR

A Vertical PERFECTLY CONDUCTING PARALlELEPIPED HAVING A CROSS

SECTIONAL AREAS OF $2 \times 2 \mathrm{~m}^{2}$. THE VERTICAL CONDUCTOR IS EXCITED AT ITs BotTom By A $1 \mathrm{~m}$ High Lumped CurRent Source, Which Produces A Gaussian PUlse Having a Half PEAK WidTh OF 33 OR 67 ns

\begin{tabular}{l|rrrrr}
\hline Half-peak & \multicolumn{5}{c}{$z^{\prime}, \mathrm{m}$} \\
\cline { 2 - 6 } width, ns & 0 & 10 & 20 & 50 & 100 \\
\hline $33 \mathrm{~ns}$ & 100 & 66 & 59 & 52 & 47 \\
$67 \mathrm{~ns}$ & 100 & 74 & 68 & 61 & 56 \\
\hline
\end{tabular}

conductor, and Table IV on the pulse width or the frequency content of excitation. It is clear from Tables II to IV that the current attenuation becomes more pronounced as the source height decreases, the thickness of vertical conductor increases, and the pulse width decreases (higher frequency content increases).

As seen in Fig. 7, current attenuation is most pronounced in the bottom part of vertical conductor (near ground). Since there is an imposed current distribution (no field boundary condition to satisfy) over the source height, there is less pronounced attenuation in the case of a longer source at the bottom of the conductor.

As seen in Table I, the magnitude of incident downward vertical electric field generated by $I_{\text {inc }}$ depends weakly on the horizontal distance from the conductor axis when the horizontal distance is much smaller than the height above ground. On the other hand, the magnitude of an upward vertical electric field produced by a single-cycle bipolar current pulse, which roughly represents $I_{\text {scat }}$ and has a negative initial half cycle, along a short dipole, decreases rapidly as the horizontal distance 
increases (see Appendix IV). Therefore, a larger $I_{\text {scat }}$ is needed to compensate the incident downward vertical electric field on the conductor surface as the conductor radius becomes larger. This is the reason why current pulse attenuation is more pronounced for a larger thickness conductor.

It is clear from (3) that the magnitude of the downward vertical electric field produced by $I_{\text {inc }}$ along a vertical conductor is independent of frequency if $v=c$ (Thottappillil et al. [17]). On the other hand, the magnitude of the vertical electric field produced by a short current dipole becomes smaller as the frequency gets higher (see Appendix IV). Within a few meters from the short dipole, the static component of electric field, which is related to the time integral of current, is dominant. Therefore, the electric field produced by the dipole at such horizontal distances (representing the thickness of the conductor) becomes smaller as the pulse width gets smaller (its higher frequency content increases) if the magnitude remains the same. As a result, in order to compensate the incident electric field on the conductor surface, the magnitude of $I_{\text {scat }}$ needs to be larger as the pulse width gets smaller (higher frequency content gets larger). This is the reason why a more narrow current pulse exhibits a more pronounced attenuation.

The risetime of the Gaussian current pulse in Fig. 7 becomes only about $10 \%$ longer within the bottom $20 \mathrm{~m}$ or so than that of the injected waveform and remains essentially the same beyond that region. On the other hand, if we inject a current pulse representative of lightning subsequent return strokes (Nucci et al. [13]), which is characterized by a broader frequency spectrum than the 67-ns wide Gaussian pulse, into the vertical perfectly conducting parallelepiped shown in Fig. 5, the pulse risetime becomes appreciably longer as the current pulse propagates upward (see Fig. 11). This is because higher frequency components are subject to considerably stronger attenuation than lower frequency components.

\section{NONUNIFORM TRANSMISSION-LINE APPROXIMATION}

Now we will consider a nonuniform transmission line approximation (e.g., Wagner and Hileman [25]; Menemenlis and Chun [26]) and show that it is consistent with our scattering theory analysis given in Sections II-IV. In this approximation, the apparent attenuation of current with height can be attributed to waves reflected back to the source. The effect is more pronounced near the bottom of the vertical conductor.

Fig. 12 shows a lossless nonuniform transmission line excited by a current source of zero length. Although Haase and Nitsch [27], [28] and Haase et al. [29] have recently derived telegrapher's equations for nonuniform transmission lines in the frequency domain, we will use a simplified approach assuming that the vertical perfectly conducting wire above ground can be represented by a lossless transmission line whose characteristic impedance increases with height as $60 \cosh ^{-1}\left(z^{\prime} / r\right)$ (e.g., Cheng [30]). This expression gives the characteristic impedance in ohm of a horizontal perfectly conducting wire of radius $r$ (not to be confused with the radial distance in (2) and (3) and in Fig. 4) at a height $z^{\prime}$ above perfectly conducting ground. However, such an approach is often used in lightning mod-

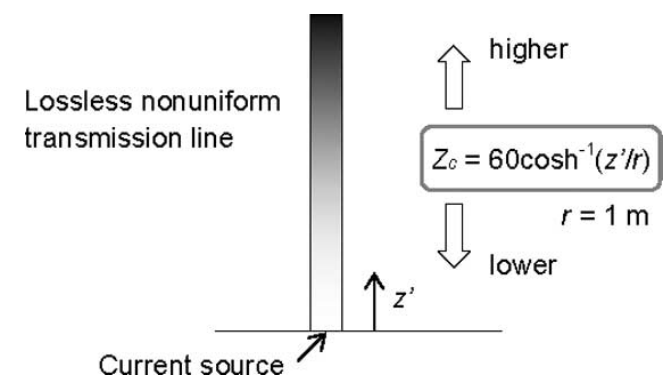

Fig. 12. A lossless nonuniform transmission line, representing a vertical conductor above ground or, equivalently, a vertical conductor and its image, excited by a current source. The characteristic impedance $Z_{c}$ is assumed to vary with height $z^{\prime}$ as $60 \cosh ^{-1}\left(z^{\prime} / r\right)$. The radius of the vertical conductor $r$ is set to 1 $\mathrm{m}$. The current source produces a Gaussian pulse having a magnitude of $1 \mathrm{kA}$ and a half-peak width of $67 \mathrm{~ns}$.

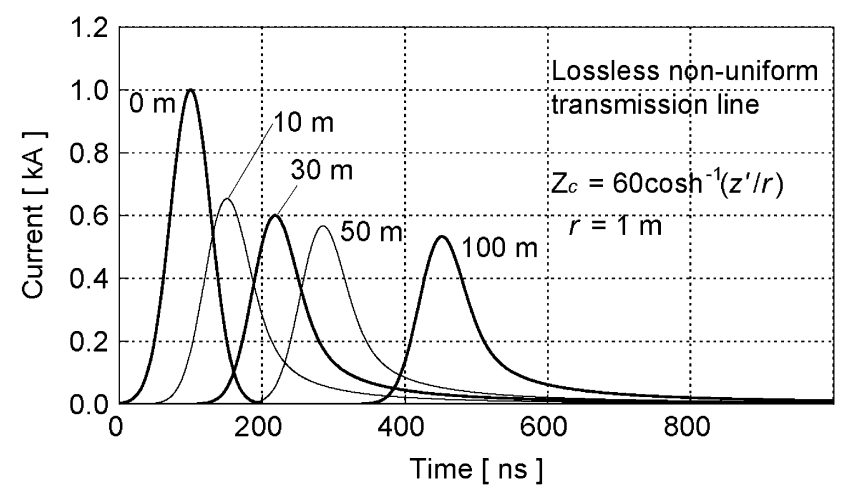

Fig. 13. Current waveforms at different heights calculated for the nonuniform transmission line shown in Fig. 12, to be compared with Fig. 7. Values of $Z_{c}$ at $10,30,50$, and $100 \mathrm{~m}$ are $180,246,276$, and $318 \Omega$, respectively. The half peak width of a Gaussian pulse injected at the botom is $67 \mathrm{~ns}$.

eling (e.g., Bazelyan et al. 1978 [31]), since there is no exact equation for the characteristic impedance for a vertical nonzeroradius conductor above ground. In this analysis, the nonuniform transmission line shown in Fig. 12 is divided into $3 \mathrm{~m}$ uniform transmission line segments whose constant characteristic impedances are given by $60 \cosh ^{-1}\left(z^{\prime} / r\right)$. The current source was assumed to produce a Gaussian pulse having a magnitude of $1 \mathrm{kA}$ and a half-peak width of $67 \mathrm{~ns}$ (the same as in Sections II-IV). The travel time of current waves along a 3-m long segment is $10 \mathrm{~ns}$. A traveling wave analysis method, the so-called Bergeron method (Dommel [32]), solving standard telegrapher's equations, was used to compute currents along such a discretized nonuniform transmission line. The results are shown in Fig.13. The treatment of reflections in the Bergeron method is qualitatively illustrated in Fig. 14. Note that the $\cosh ^{-1}$ expression for the characteristic impedance reduces to $60 \ln \left(2 z^{\prime} / r\right)$ when $z^{\prime} \gg r \quad\left(\cosh ^{-1} x=\ln \left[x+\left(x^{2}-1\right)^{1 / 2}\right]\right.$ for $x>1)$, which yields almost the same current profile as that shown in Fig. 13.

From comparison of Figs. 7 and 13, one can see that the lossless nonuniform transmission line shown in Fig. 12 can reasonably reproduce the current pulse attenuation and the lengthened wavetail, obtained from the full-wave analysis using the FDTD method for the $2 \times 2 \mathrm{~m}^{2}$ vertical perfectly 


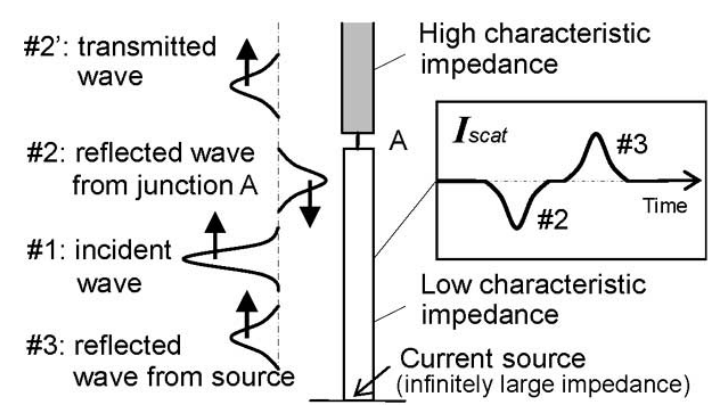

Fig. 14. A transmission line composed of two lossless uniform transmission line sections connected in series, excited by a current source. The characteristic impedance of the section above junction point $\mathrm{A}$ is higher than that of the section below $\mathrm{A}$. When an incident upward propagating positive current wave (\#1) encounters junction A, a downward negative (reflected) current wave (\#2) is produced there. When the downward negative reflected current wave (\#2) encounters the current source (infinitely large impedance), an upward positive (reflected) current wave (\#3) is produced.

conducting parallelepiped above ground (see Section III). The observed small differences in current decay seen in Figs. 7 and 13 are likely to be due to different cross sections used in the FDTD $\left(2 \times 2 \mathrm{~m}^{2}\right)$ and nonuniform transmission line $(1 \mathrm{~m} \mathrm{ra}-$ dius circle) simulations. In the case of a shorter injected current pulse (half-peak width of $33 \mathrm{~ns}$ ), the waveforms of a current pulse at different heights calculated using the nonuniform transmission line shown in Fig. 12 are in good agreement with those calculated using the FDTD method for the vertical perfectly conducting parallelepiped (neither of these waveforms is shown in this paper).

We now qualitatively discuss the current pulse attenuation and lengthening of its tail, predicted by the nonuniform transmission line approach. Fig. 14 shows the bottom two sections of discretized nonuniform transmission line presented in Fig. 12. When an incident upward propagating positive current wave (\#1) encounters junction A, a downward negative (reflected) current wave (\#2) is produced there. The reflected current wave is negative because the characteristic impedance above $\mathrm{A}$ is greater than below A. The apparent current attenuation with height along the nonuniform transmission line (Fig. 13) can be attributed to such waves reflected back to the current source. When the downward negative reflected current wave (\#2) encounters the current source (infinitely large impedance), an upward positive (reflected) current wave (\#3) is produced. This latter reflection is apparently responsible for the lengthened tail of the total current waveform (Fig. 13).

The time variations of the time integral of current pulse at each height for this nonuniform transmission line, which are not shown in this paper, are essentially identical to those calculated using the FDTD method for the vertical perfectly conducting parallelepiped (Fig. 8). Note that an attenuated current propagating along a vertical conductor above ground produces a non-TEM wave (Baba and Rakov [7]). Therefore, a similarly attenuated current pulse, which propagates along the nonuniform transmission line, also produces a non-TEM wave.

Since the Bergeron method employs standard telegrapher's equations for each segment of the wire, it apparently does not account for electromagnetic radiation. This fact and the simi- larity of the results obtained using the nonuniform transmission line approximation and scattering theory appear to support our speculation (see Section III) that the current attenuation can be explained without invoking the not-well-defined concept of "radiation losses." As noted above, in the nonuniform transmission line approximation, the apparent current attenuation with height can be attributed to waves reflected back to the source.

\section{SUMMARY}

\section{A. Attenuation Mechanism in Terms of the Scattering Theory}

The mechanism of apparent attenuation of current pulses as they propagate along a vertical nonzero-thickness perfect conductor above perfectly conducting ground can be visualized as follows. A reference (no interaction with the conductor, no attenuation) positive current pulse $I_{\text {inc }}$ propagating upward generates an incident spherical TEM wave, with vertical electric field on the surface of the conductor being directed downward. Cancellation of this field, as required by the boundary condition on the tangential electric field on the surface of a perfect conductor, gives rise to a "scattered" current $I_{\text {scat }}$. This scattered current $I_{\text {scat }}$ modifies $I_{\text {inc }}$, so that the resultant total current pulse $I_{\text {tot }}$ appears attenuated as it propagates along the vertical conductor. Thus it appears that the field scattering (not present in the case of zero-thickness conductor) causes current attenuation with height. The attenuation of the total current pulse is accompanied by the lengthening of its tail, such that the total charge transfer is independent of height. The electromagnetic field structure associated with an attenuated current distribution along a vertical conductor above ground is non-TEM.

\section{B. Attenuation Mechanism in Terms of the Nonuniform Transmission Line Theory}

A nonuniform transmission line whose characteristic impedance increases with increasing height is shown to reasonably reproduce the current pulse attenuation and lengthening of its tail predicted by the scattering theory. In this representation, the apparent current attenuation with height can be attributed to waves reflected back to the source.

\section{Dependence on Height}

The magnitude of the incident downward vertical electric field on the conductor surface produced by $I_{\mathrm{inc}}$ is approximately inversely proportional to height if the height is much larger than the conductor thickness. This is the reason for less pronounced current attenuation with increasing height.

\section{Dependence on Pulse Width}

The magnitude of the incident vertical electric field on the surface of a perfect conductor, produced by $I_{\text {inc }}$, is independent of frequency if $v=c$. On the other hand, the magnitude of the scattered vertical electric field is related to the time integral of $I_{\text {scat }}$. Therefore, if the pulse width of incident vertical electric field on the conductor surface, to be cancelled by the scattered vertical electric field, gets narrower while its magnitude is the 


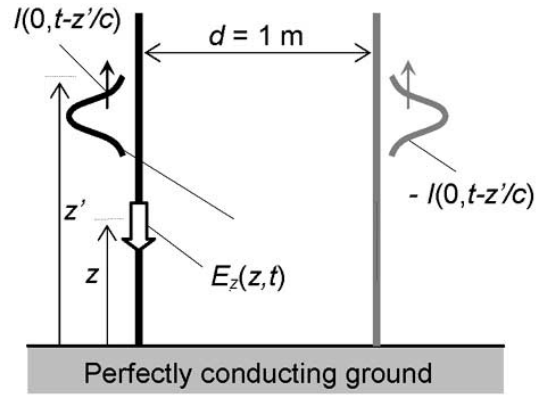

Fig. 15. Two parallel vertical phased current source arrays of zero thickness above perfectly conducting ground. The arrays simulate incident unattenuated opposite polarity current pulses having an amplitude of $1 \mathrm{kA}$ propagating upward with $v=c$. The spacing between the arrays is $d=1 \mathrm{~m}$.

same, a larger $I_{\text {scat }}$ is needed. This is the reason why more narrow current pulses exhibit a stronger attenuation.

\section{E. Implications for Lightning Models}

Our finding that a current pulse propagating along a vertical nonzero-thickness conductor attenuates significantly near the ground has important implications for lightning modeling, since this is the region of primary interest when the generation of lightning fields at early times is considered. Lightning returnstroke models with an imposed current distribution along the entire channel represent a useful engineering tool, but should be used with caution in studying lightning physical processes. A vertical conductor above ground, representing a lightning channel or a tall strike object, generally cannot support unattenuated propagation of current waves, even if all losses are neglected.

\section{APPENDIX I}

\section{A. Incident E-Field for Two Parallel Vertical Phased Current Source Arrays: Analytical Solution}

Fig. 15 shows two parallel vertical phased current source arrays of zero thickness on perfectly conducting ground. The arrays represent incident unattenuated opposite polarity current pulses having the same amplitude and propagating upward with $v=c$.

Table V shows magnitudes of downward vertical electric field along the axis of the left array, calculated using (3). Note that retardation of wave propagation from the right array is neglected in this calculation. In Table $\mathrm{V}$, magnitudes of downward vertical electric field in the case of a single array are also shown for reference. It follows from Table $\mathrm{V}$ that the vertical electric field (to be compensated by the scattered field) decreases much faster in the case of two arrays than in the case of a single array and vanishes within heights exceeding several times the spacing between the two arrays. This result indicates that a current pulse on a horizontal conductor above perfectly conducting ground would attenuate less than that on a single vertical conductor above ground.

\section{TABLE V}

Magnitudes of Downward VerTiCAL Electric Field in kV/m AT A HEIGHT $z$ ALONG THE AXIS $(x=0$ OR $x \rightarrow 0$ ) OF THE LEFT PHASED CURRENT Source Array Above Ground Plane Shown in Fig. 15, Calculated Using (3). RETARDATION OF WAVE PROPAGATION From the Right PHASED CURRENT Source ARRaY Is NEGLECTED. MAGNITUdES OF DOWNWARD

Vertical Electric Field in the CASE OF a Single Phased Source ARRay ARE ADDED FOR REFERENCE. DOWNWARd FIELD Is DEFINED AS Positive

\begin{tabular}{l|rrrr}
\hline \multirow{2}{*}{ Configuration } & \multicolumn{4}{|c}{$z, \mathrm{~m}$} \\
\cline { 2 - 5 } & 0.1 & 1 & 10 & 100 \\
\hline Two parallel vertical arrays & 540 & 18 & 0.03 & 0.00 \\
Single vertical array & 600 & 60 & 6.0 & 0.60 \\
\hline
\end{tabular}

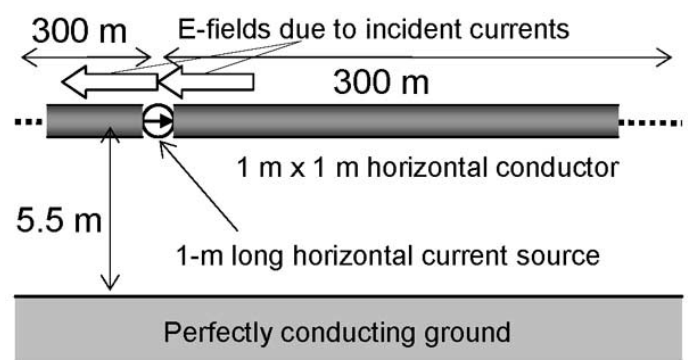

(a)

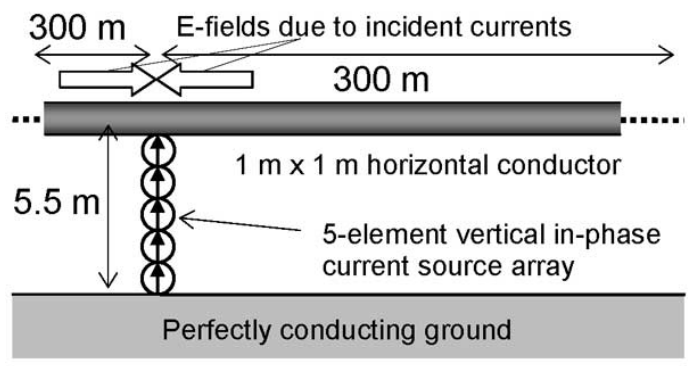

(b)

Fig. 16. A horizontal conductor having a cross sectional area of $1 \times 1 \mathrm{~m}^{2}$ placed $5.5 \mathrm{~m}$ above perfectly conducting ground, to be analyzed using the FDTD method: (a) A $1 \mathrm{~m}$ long current source is inserted in the middle of 600 $\mathrm{m}$ long horizontal wire. (b) A $5 \mathrm{~m}$ vertical in-phase current source array is connected to the middle of a $600 \mathrm{~m}$ long horizontal wire. Each current source produces a Gaussian pulse having a magnitude of $1 \mathrm{kA}$ and a half-peak width of $67 \mathrm{~ns}$. The white arrows indicate the directions of longitudinal electric fields generated by incident unattenuated current pulses.

\section{B. Total Current for Horizontal Configurations: Numerical Solution}

Fig. 16 shows a horizontal perfectly conducting parallelepiped having a cross sectional area of $1 \times 1 \mathrm{~m}^{2}$ placed $5.5 \mathrm{~m}$ above perfectly conducting ground, to be analyzed using the FDTD method. The working volume for this analysis is $40 \times 620 \times 40 \mathrm{~m}^{3}$ and is surrounded by perfectly matched layers (PML) of thickness $10 \mathrm{~m}$, except for the bottom, where the volume is limited by the perfectly conducting plane. The overall rectangular volume shown in Fig. 16 is divided into $1 \times 1 \times 1 \mathrm{~m}^{3}$ cubic cells. The white arrows in Fig. 16 indicate the directions of the longitudinal electric fields generated by the incident unattenuated current pulses on horizontal wires.

In Fig. 16(a), which is quite similar to the configuration of Fig. 15, both right-directed positive and left-directed negative 


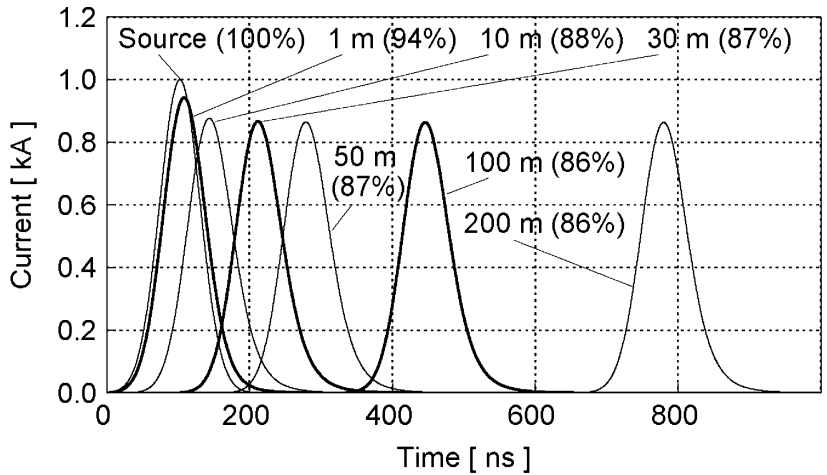

(a)

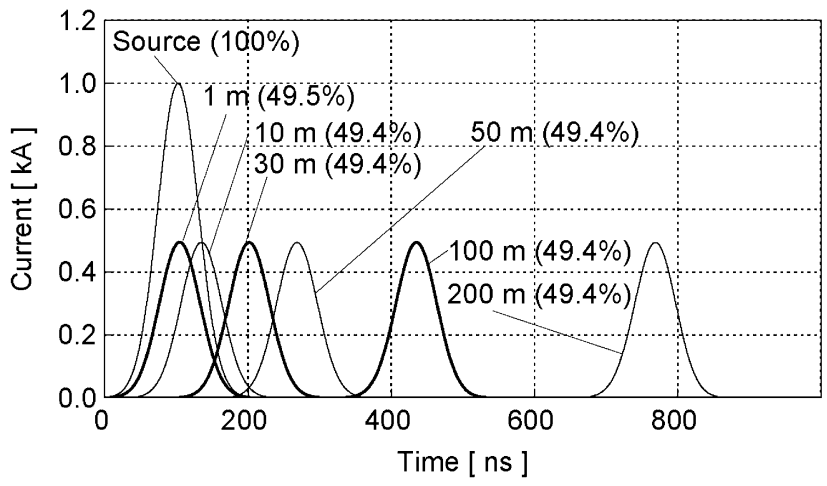

(b)

Fig. 17. Current waveforms at different distances from the current injection point calculated using the FDTD method for a horizontal conductor placed $5.5 \mathrm{~m}$ above perfectly conducting ground: (a) For the configuration of Fig. 16(a). (b) For that of Fig. 16(b).

(incident unattenuated) current pulses will produce left-directed incident electric fields. In Fig. 16(b), the longitudinal incident electric field near the current injection point would be much less than that in Fig. 16(a). Indeed, the incident right- and leftdirected positive current pulses will produce left- and rightdirected incident electric fields, respectively, which will tend to cancel each other.

Fig. 17 shows current waveforms at different distances from the current injection point calculated using the FDTD method for each of the two cases presented in Fig. 16. The FDTD simulation results are consistent with what we expected from the examination of longitudinal incident electric fields generated by the incident current pulses. This indicates that longitudinal electric fields generated by the incident current pulses are closely related to current attenuation. Note that, even in Fig. 17(a), a current pulse decays only within the first $20 \mathrm{~m}$ or so, and it propagates with little or no attenuation beyond this region, where the incident longitudinal electric field essentially vanishes. This is generally referred to as a "quasi-TEM" field structure.

\section{APPENDIX II}

\section{COMPARISON OF FDTD SIMULATION WITH AN ANALYTICAL SOLUTION}

Chen [15] has derived an approximate analytical equation for the transient current $I\left(z^{\prime}, t\right)$ along an infinitely long, perfectly

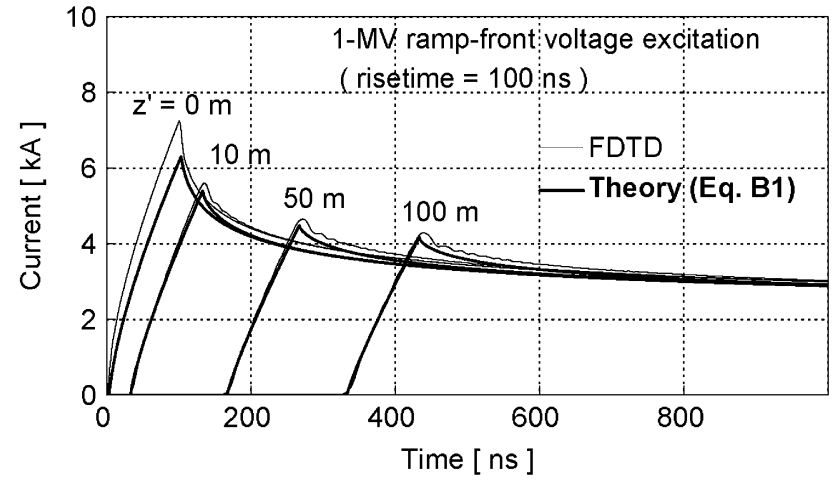

Fig. 18. Current waveforms at different heights, calculated using the FDTD method for a vertical perfectly conducting parallelepiped having a cross sectional area of $2 \times 2 \mathrm{~m}^{2}$ above a perfectly conducting plane excited at its bottom by a $1 \mathrm{~m}$ high lumped voltage source and those calculated using (II1) for a vertical perfectly conducting cylinder of $1 \mathrm{~m}$ radius above a perfectly conducting plane excited at its bottom by a delta-gap voltage source. In both cases, the voltage sources produce a ramp front wave having a magnitude of $1 \mathrm{MV}$ and a risetime of $100 \mathrm{~ns}$.

conducting cylinder in air, excited in the middle by a delta gap step voltage, $\mathrm{V}$, source. This equation is reproduced below.

$$
I\left(z^{\prime}, t\right)=\frac{2 \mathrm{~V}}{\eta_{0}} \tan ^{-1}\left(\frac{\pi}{2 \ln \left(\sqrt{c^{2} t^{2}-z^{\prime 2}} / a\right)}\right)
$$

where $\eta_{0}$ is the free space impedance $(120 \pi), \ln$ is the natural logarithm, and $a$ is the radius of the cylinder. Chen's [15] approximate expression yields quite accurate results that are almost identical to those given by the exact formula (Wu [14]). If we apply (II1) to a vertical cylinder placed on a perfectly conducting plane and excited at its bottom, we have only to multiply the magnitude of resultant current by 2 , in order to account for the image source.

Fig. 18 shows current waveforms at different heights, $z^{\prime}$, calculated using the FDTD method for a vertical perfectly conducting parallelepiped having a cross-sectional area of $2 \times 2 \mathrm{~m}^{2}$ on a perfectly conducting plane excited at its bottom by a $1 \mathrm{~m}$ high lumped voltage source and those calculated using (II1) for a vertical perfectly conducting cylinder of $1 \mathrm{~m}$ radius excited at its bottom by a delta-gap voltage source. In both cases the voltage sources are assumed to produce a ramp-front wave having a magnitude of $1 \mathrm{MV}$ and a risetime of $100 \mathrm{~ns}$. Since (II1) is the solution for a step voltage excitation, we obtained the response to our ramp-front voltage wave using numerical convolution. The waveforms calculated using the FDTD method agree reasonably well with those calculated using (II1). Note that the small difference in current waveforms at $z^{\prime}=0 \mathrm{~m}$ is probably due to the difference in source size: $1 \mathrm{~m}$ in the FDTD simulation versus zero in (II1). It is also worth noting that as the radius, $a$, of the cylinder approaches zero, current predicted by (II1) approaches zero as well, unless voltage, $V$, is infinitely large.

\section{APPENDIX III}

\section{E-FiEld STRUCTURE AROUND A VERTICAL NONZERO-THICKNESS PERFECT CONDUCTOR}

We now examine the electromagnetic field structure in air surrounding the $2 \times 2 \times 300 \mathrm{~m}^{3}$ or $1 \times 1 \times 300 \mathrm{~m}^{3}$ vertical perfect 
TABLE VI

Magnitudes of Electric Field (In Percent of the Magnitude of the CORRESPONDING EleCtric Field OF SPHERICAL TEM WaVE) AT DifFERENT PoINTS $(r, \theta)$ (SEE Fig. 4) AROUND THE $2 \times 2 \times 300 \mathrm{~m}^{3}$ VERTICAL Conductor (Fig. 5), Calculated Using THE FDTD Method. THE VERTICAL CONDUCTOR IS EXCITED AT ITS BOTTOM BY A $1 \mathrm{~m}$ HIGH LUMPED Current Source, Which Produces a Gaussian Pulse HaVing a HalF PEAK WIDTH OF $67 \mathrm{~ns}$

\begin{tabular}{r|cc|c}
\hline \multirow{2}{*}{$r, \mathrm{~m}$} & \multicolumn{2}{|c|}{$\theta=\pi / 4$} & $\theta=\pi / 2$ \\
\cline { 2 - 4 } & vertical & horizontal & vertical \\
\hline 14 & 66 & 95 & 83 \\
35 & 63 & 76 & 73 \\
71 & 63 & 70 & 71 \\
141 & 62 & 66 & 70 \\
\hline
\end{tabular}

\section{TABLE VII}

Magnitudes of Electric Field (In Percent of the Magnitude of the CORRESPONDING ELECTRIC FIELD OF A SPHERICAL TEM WAVE) AT DifFerent Points $(r, \theta)$ (SEe Fig. 4) AROUND THE $1 \times 1 \times 300 \mathrm{~m}^{3}$ VERTICAL CONDUCTOR (FIG. 5), CAlculated Using THE FDTD Method. THE VERTICAL CONDUCTOR IS EXCITED AT ITS BOTTOM BY A $1 \mathrm{~m}$ HigH LUMPED Current Source, Which Produces a Gaussian Pulse Having a Half PEAK WIDTH OF $67 \mathrm{~ns}$

\begin{tabular}{c|cc|c}
\hline \multirow{2}{*}{$r, \mathrm{~m}$} & \multicolumn{2}{|c|}{$\theta=\pi / 4$} & $\theta=\pi / 2$ \\
\cline { 2 - 4 } & vertical & horizontal & vertical \\
\hline 14 & 74 & 100 & 90 \\
35 & 70 & 82 & 80 \\
71 & 69 & 76 & 77 \\
141 & 69 & 72 & 76 \\
\hline
\end{tabular}

conductor (Fig. 5). Tables VI and VII show the magnitudes of vertical and horizontal electric fields at different points around these vertical conductors, calculated using the FDTD method. Note that, in calculations presented in this Appendix, the spacing between the vertical conductor axis and the right-hand side absorbing boundary wall in Fig. 5 was moved from 20 to $150 \mathrm{~m}$. In a spherical TEM wave, vertical and horizontal electric fields at $\theta=\pi / 4$, and vertical electric field at $\theta=\pi / 2$ should be the same. One can see from Tables VI and VII that the overall electromagnetic field structure far away from the vertical conductor approaches that of TEM wave.

\section{APPENDIX IV}

\section{VERTICAL E-FIELD PRODUCED By A 1-m LONG CURRENT DiPOLE}

In order to investigate the dependencies of scattered current magnitude on the thickness of vertical conductor and on the pulse width, we calculated vertical electric fields produced by a 1-m long vertical current dipole shown in Fig. 19. This current dipole is energized by a single cycle, sinusoidal current pulse, which has a negative initial half cycle, a magnitude of $1 \mathrm{kA}$, and a total duration $\tau=200 \mathrm{~ns}(f=5 \mathrm{MHz})$ or $100 \mathrm{~ns}(f=$ $10 \mathrm{MHz}$ ). This current pulse is a rough approximation to the bipolar scattered current (Fig. 9).

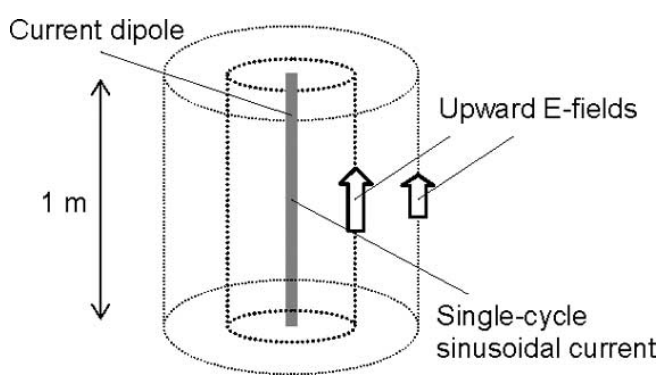

Fig. 19. A $1 \mathrm{~m}$ long vertical current dipole, on which a single cycle sinusoidal current pulse flows.

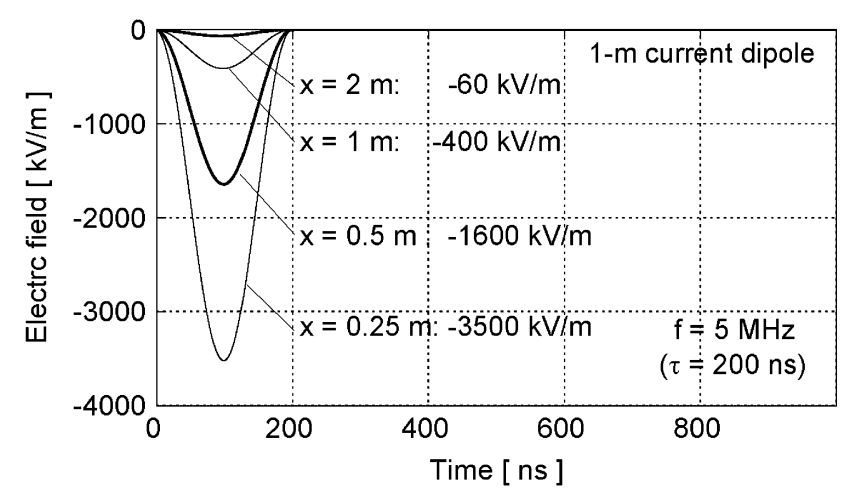

(a)

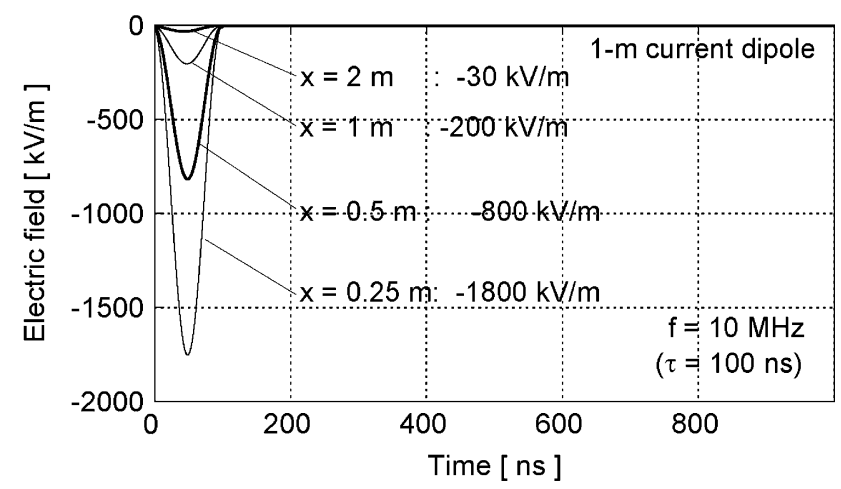

(b)

Fig. 20. Waveforms of vertical electric field produced by a single cycle sinusoidal current pulse on a $1 \mathrm{~m}$ long vertical dipole: (a) $f=5 \mathrm{MHz}$ (total duration $\tau=200 \mathrm{~ns})$. (b) $f=10 \mathrm{MHz}(\tau=100 \mathrm{~ns})$. Downward electric field is defined as positive.

Fig. 20(a) shows waveforms of upward vertical electric field at different horizontal distances from the dipole axis. It is clear from Fig. 20(a) that the magnitude of upward vertical electric field produced by the dipole decreases rapidly with increasing the horizontal distance.

Fig. 20(b) is similar to Fig. 20(a) but for $\tau=100 \mathrm{~ns}(f=$ $10 \mathrm{MHz}$ ). It is clear from Fig. 20(b) that the magnitude of downward vertical electric field produced by the dipole decreases as the pulse becomes narrower. Within few meters from the 1-m current dipole, the static component of electric field, which is related to time integral of current, is dominant. Therefore, the electric field produced by the dipole at such horizontal distances decreases as the pulse gets narrower while its magnitude is the same. 


\section{ACKNOWLEDGMENT}

The authors would like to thank R. Thottappillil, M. A. Uman, and three anonymous reviewers for their valuable comments on the paper.

\section{REFERENCES}

[1] R. F. Harrington, Field Computation by Moment Methods. New York: Macmillan, 1968.

[2] K. S. Yee, "Numerical solution of initial boundary value problems involving Maxwell's equations in isotropic media," IEEE Trans. Antennas Propag., vol. 14, no. 3, pp. 302-307, Mar. 1966.

[3] V. A. Rakov and M. A. Uman, "Review and evaluation of lightning return stroke models including some aspects of their application," IEEE Trans. Electromagn. Compat., vol. 40, no. 4, pp. 403-426, Nov. 1998.

[4] A. S. Podgorski and J. A. Landt, "Three dimensional time domain modeling of lightning," IEEE Trans. Power Del., vol. PWRD-2, no. 3, pp. 931938, Jul. 1987.

[5] R. Moini, B. Kordi, G. Z. Rafi, and V. A. Rakov, "A new lightning return stroke model based on antenna theory," J. Geophys. Res., vol. 105, no. D24, pp. 29693-29702, 2000.

[6] B. Kordi, R. Moini, W. Janischewskyj, A. M. Hussein, V. O. Shostak, and V. A. Rakov, "Application of the antenna theory model to a tall tower struck by lightning," J. Geophys. Res., vol. 108, no. D17, 2003.

[7] Y. Baba and V. A. Rakov, "On the transmission line model for lightning return stroke representation," Geophys. Res. Lett., vol. 30, no. 24, 2003.

[8] C. C. Bantin, "Radiation from a pulse-excited thin wire monopole," IEEE Antennas Propag. Mag., vol. 43, no. 3, pp. 64-69, 2001.

[9] B. Kordi, R. Moini, and V. A. Rakov, "Comment on 'Return stroke transmission line model for stroke speed near and equal that of light' by R. Thottappillil, J. Schoene, and M. A. Uman," Geophys. Res. Lett., vol. 29, no. $10,2002$.

[10] - "Comparison of lightning return stroke electric fields predicted by the transmission line and antenna theory models," in Proc. 15th Int. Zurich Symp. Electromagn. Compat., 102P2, Zurich, 2003, pp. 551-556.

[11] Y. Baba and M. Ishii, "Characteristics of electromagnetic return-stroke models," IEEE Trans. Electromagn. Compat., vol. 45, no. 1, pp. 129-135, Feb. 2003.

[12] L. Grcev, F. Rachidi, and V. A. Rakov, "Comparison of electromagnetic models of lightning return strokes using current and voltage sources," in Proc. 12th Int. Conf. Atmospheric Electricity, Versailles, France, 2003, pp. 593-596.

[13] C. A. Nucci, G. Diendorfer, M. A. Uman, F. Rachidi, M. Ianoz, and C. Mazzetti, "Lightning return stroke current models with specified channel-base current: A review and comparison,"J. Geophys. Res., vol. 95, no. D12, pp. 20395-20408, 1990.

[14] T. T. Wu, "Transient response of a dipole antenna," J. Math. Phys., vol. 2, pp. 892-894, 1961.

[15] K. C. Chen, "Transient response of an infinite cylindrical antenna," IEEE Trans. Antennas Propag., vol. AP-31, no. 1, pp. 170-172, Jan. 1983.

[16] R. Lee and D. G. Dudley, "Transient current propagation along a wire penetrating a circular aperture in an infinite planar conducting screen," IEEE Trans. Electromagn. Compat., vol. 32, no. 2, pp. 137-143, May 1990.

[17] R. Thottappillil, J. Schoene, and M. A. Uman, "Return stroke transmission line model for stroke speed near and equal that of light," Geophys. Res. Lett., vol. 28, no. 18, pp. 3593-3596, 2001.

[18] R. Thottappillil, M. A. Uman, and N. Theethayi, "Electric and magnetic fields from a semi-infinite antenna above a conducting plane," J. Electrostatics, vol. 61, no. 3-4, pp. 209-221, Jul. 2004.

[19] M. A. Uman and D. K. McLain, "The magnetic field of the lightning return stroke," J. Geophys. Res., vol. 74, pp. 6899-6910, 1969.

[20] R. Thottappillil and M. A. Uman, "Reply to the "Comment on "Return stroke transmission line model for stroke speed near and equal that of light” by R. Thottappillil, J. Schoene, and M. A. Uman' by B. Kordi, R. Moini, and V. A. Rakov"," Geophys. Res. Lett., vol. 29, no. 10, 2002.

[21] J. L. Bermudez, M. Rubinstein, F. Rachidi, F. Heidler, and M. Paolone, "Determination of reflection coefficients at the top and bottom of elevated strike objects struck by lightning," J. Geophys. Res., vol. 108, no. D14, 2003.
[22] C. A. Balanis, Antenna Theory: Analysis and Design, 2nd ed., New York, Wiley, 1997.

[23] V. A. Rakov, "Lightning return stroke speed: A review of experimental data," in Proc. 27th Int. Conf. Lightning Protection, Avignon, France, 2004, 1c.1.

[24] J. P. Berenger, "A perfectly matched layer for the absorption of electromagnetic waves," J. Comput. Phys., vol. 114, pp. 185-200, 1994.

[25] C. F. Wagner and A. R. Hileman, "A new approach to the calculation of the lightning performance of transmission lines III-A simplified method: Stroke to tower," Trans. AIEE Pow. Appar. Syst., vol. 79, pp. 589-603, 1960.

[26] C. Menemenlis and Z. T. Chun, "Wave propagation on nonuniform line," IEEE Trans. Power App. Syst., vol. PAS-101, no. 4, pp. 833-839, Apr. 1982.

[27] H. Haase and J. Nitsch, "Investigation of nonuniform transmission line structures by a generalized transmission-line theory," in Proc. 15th Int. Zurich Symp. Electromagn. Compat., Zurich, Feb. 2003a, pp. 597-602.

[28] — "Generalized transmission-line theory for the treatment of nonuniform multiconductor transmission lines," Int. J. Applied Electromagnetics and Mechanics, vol. 17, no. 1-3, 2003b.

[29] H. Haase, J. Nitsch, and T. Steinmetz, "Transmission-line super theory: A new approach to an effective calculation of electromagnetic interactions," URSI Radio Science Bull., no. 307, pp. 33-60, Dec. 2003.

[30] D. K. Cheng, Fundamentals of Engineering Electromagnetics. Reading, MA: Addison-Wesley, 1993.

[31] E. M. Bazelyan, B. N. Gorin, and V. I. Levitov, Physical and Engineering Foundations of Lightning Protection. Leningrad, U.S.S.R.: Gidrometeoizdat, 1978.

[32] H. W. Dommel, "Digital computer solution of electromagnetic transients in single and multiphase networks," IEEE Trans. Power App. Syst., vol. PAS-88, no. 4, pp. 388-399, 1969.

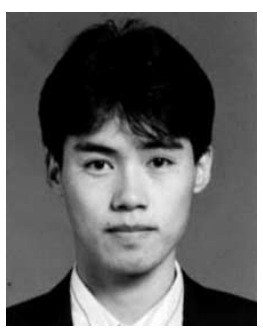

Yoshihiro Baba (S'95-M'99) received the B.S., M.S., and Dr.Eng. degrees from the University of Tokyo, Tokyo, Japan, in 1994, 1996 and 1999, respectively.

$\mathrm{He}$ is an Associate Professor of the Department of Electrical Engineering, Doshisha University, Kyoto, Japan. From April 2003 to August 2004, he was a Visiting Scholar at the University of Florida on sabbatical leave from Doshisha University. He is the author or coauthor of over 20 papers published in reviewed journals.

Dr. Baba is a member of AGU and IEE

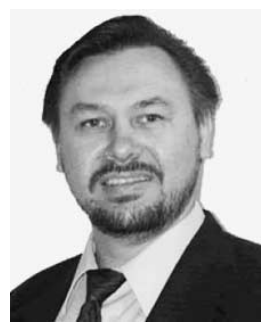

Vladimir A. Rakov (SM'96-F'03) received the M.S., and Ph.D. degrees from Tomsk Polytechnical University (Tomsk Polytechnic), Tomsk, Russia, in 1977 and 1983, respectively.

$\mathrm{He}$ is a Professor of the Department of Electrical and Computer Engineering, University of Florida (UF), Gainesville. He is the author or coauthor of one book, over 30 patents, and over 300 papers and technical reports on various aspects of lightning, with over 120 papers being published in reviewed journals. From 1977 to 1979, he worked as an Assistant Professor of Electrical Engineering at Tomsk Polytechnic. In 1978, he became involved in lightning research at the High Voltage Research Institute, a division of Tomsk Polytechnic, where from 1984 to 1994 he held the position of Director of the Lightning Research Laboratory.

Prof. Rakov is Chairman of the Technical Committee on Lightning of the biennial International Zurich Symposium on Electromagnetic Compatibility and former Chairman of the AGU Committee on Atmospheric and Space Electricity (CASE). He is a Fellow of AMS and a member of AGU, SAE, and ASEE. 